\title{
ESTANHO: UM METAL ESTRATÉGICO ONTEM E HOJE
}

\author{
Geraldo M. de Lima*,a, (1)
}

aDepartamento de Química, Instituto de Ciências Exatas, Universidade Federal de Minas Gerais, 31270-901 Belo Horizonte - MG, Brasil

Recebido em 23/06/2019; aceito em 17/10/2019; publicado na web em 14/11/2019

\begin{abstract}
TIN: A STRATEGIC METAL YESTERDAY AND TODAY. Tin chemistry sometimes is considered boring, colourless and with irrelevant applications. Archaeological, historical and technological facts show otherwise. These facts demonstrate that tin became vital for man in a distant past and its importance lasts thereafter. In this paper, it is introduced some historical arguments that reveal the significance of tin or cassiterite as strategic materials in ancient tools, beginning from the Bronze Age. This paper shows as well the importance of this metal in current times. It also describes the importance of Brazil in this scenario, given the large reserves of cassiterite and its crucial participation in the world market. In addition, it provides a revision of the main classes of tin compounds $\{\mathrm{Sn}$ (IV) and Sn (II), among other oxidation states \}. Additionally, it summarises some main applications of tin compounds, such as PVC stabilizers, antifouling paint and in the manufacturing of foams and polymers, discussing its strategic role in modern technologies. Finally, it highlights the importance of tin in the preparation of $\mathrm{Nb}_{3} \mathrm{Sn}$, a superconducting alloy with niobium, and in the synthesis of new materials, for example, a two-dimensional polymer, structurally similar to graphene.
\end{abstract}

Keywords: strategic role of tin; Bronze Age; cassiterite, organotins, strategic metal.

\section{INTRODUÇÃO}

Um dos diferenciais humanos em relação a outras espécies é a capacidade de produzir ferramentas e com elas efetuar operações. Ao longo da história essas habilidades contribuiram para nos consolidarmos como espécie dominante no planeta. É sabido que o homem foi adquirindo essas competências desde tempos distantes, através de uma sucessão de experiências, impossíveis de se precisar. Mas as práticas trouxeram consequências na caça, pesca, processamento de alimentos, na proteção contra feras, invasores e na sobrevivência em geral. Pedras, madeiras e ossos de animais foram utilizados na confecção de ferramentas primitivas, até serem substituidos por cobre por volta de $9.000 \mathrm{AC}$, provavelmente encontrado na natureza na forma elementar. Sua extração de fontes minerais como malaquita, foi posteriormente dominada por meio das primeiras práticas rudimentares de metalurgia. É possível que o ouro, graças aos seus atrativos visuais, já fosse conhecido dos humanos nessa época, mas por ser escasso e de baixa dureza, não tinha muita serventia. O cobre mais abundante, de fácil fusão, podia ser moldado na forma de facas, espadas, pontas de lanças e de flexas, machados e de objetos para uso geral. ${ }^{1} \mathrm{O}$ processamento do cobre por metalurgia rudimentar, período Calcolítico, marcou a época entre o Neolítico e a Era do Bronze (3500 AC). Esse último período da história só foi possível graças a existência de outro metal, o estanho ou ao seu mineral, a cassiterita, cujo processo de descoberta de tão distante, perdeu-se no tempo. Peças de bronze, embora bastante antigas, são relativamente abundantes, ao contrário das de estanho puro, que são raras. Uma das mais remotas é uma pequena folha de estanho de alto grau de pureza encontrada num sarcófago de um contemporâneo de Tutemóses III, Faraó do Egito (1479 - 1435 AC). Essas poucas evidências de objetos de estanho levam muitos estudiosos a sugerir que a obtenção do bronze é provavelmente anterior à metalurgia do estanho. ${ }^{2}$ Suspeita-se que as primeiras receitas de obtenção do bronze, liga composta por cerca de $7 / 8$ de cobre 1/8 de estanho, consistia em queimar, sob forte fluxo de ar, misturas de carvão, cassiterita e malaquita, dispostas em camadas numa fornalha, sem utilizar os metais. ${ }^{3}$

*e-mail: gmlima@ufmg.br
Das principais contribuições da Era do Bronze na Europa destaca-se o estabelecimento de fortes rotas comerciais por volta de $2000 \mathrm{AC}$. Nos duzentos anos seguintes elas se estendiam pela quase totalidade do mundo conhecido, durando até $1200 \mathrm{AC}$, quando o bronze foi substituido por ferro. ${ }^{4}$ Isso devido principalmente ao esgotamento de reservas conhecidas de cassiterita e a dificuldade de sua mineração em locais distantes dos principais centros comerciais.

As referências mais antigas que citam o estanho metálico são encontradas no Velho Testamento, nos livros de Números (31:21, 22), Ezequiel (27:12 e 18), Isaias (1:25) e Zacarias (4:10). A referência em Números pode ser anterior a 1200 AC o que estaria em concordância histórica com a descoberta daquele artefato da época de Tutemóses III. O estanho é também mencionado na obra Ilíada, onde Homero (928 AC - 898 AC) refere-se a esse metal como cassíteros. Todas essas referências convergem para o fato de que o estanho era um metal estratégico e precioso na antiguidade. ${ }^{3}$

É provável que devido à sua escassez, existia a necessidade de se esconder a verdadeira localização das antigas minas de cassiterita. Então as referências que chegaram aos dias atuais são pouco precisas. Heródoto por volta de 440 AC, refere-se à ilha de Cassitérides, como o lugar de origem do estanho do bronze grego. Especulou-se ao longo do tempo que essa ilha localizava-se na costa norte francesa, nos Açores, ou ainda nas Ilhas Sorlingas, situadas a oeste da costa sul Britânica, dentre outros lugares. ${ }^{5}$ Finalmente, a Cornualha foi identificada como fonte de estanho por volta de 8 AC na obra de Diodorus Siculus, Bibliotheca historica, mas especula-se que os Fenícius exploravam secretamente essas minas pelo menos mil anos antes. ${ }^{3}$

A obra de Plinio o Velho, Naturalis Historiae, mostra que existia uma confusão entre estanho e chumbo: um denominado de chumbo escuro e outro claro, de longe o mais valioso, era chamado pelos Gregos de cassíteros. ${ }^{2}$ Mais adiante ele descreve artefatos de cobre recobertos com estanho (stannum) e menciona o fato de o "chumbo claro" ser manufaturado na época das guerras de Trajano, Imperador Romano (98 - 117 DC).

Em cerca de $500 \mathrm{AC}$ passou-se a representar esse elemento pelo símbolo originado da corruptela da primeira e última letra da palavra

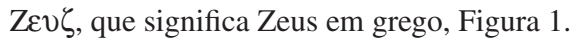




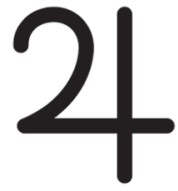

Figura 1. Primeiro símbolo do estanho

Algumas propriedades do estanho e de suas ligas foram descritas por Geber (721 - 815 DC) em seu Summa Perfectionis Magisterii. Somente no século XVII é que surgiram os primeiros compostos químicos, embora existam suspeitas de que o hoje conhecido citrato de estanho era utilizado pelos egípcios na confecção de pigmentos. Libavius, descreve a preparação de um líquido fumegante chamado liquor argentii vivi sublimati ou spiritus argentii vivi sublimati obtido da destilação de uma mistura de estanho com cloreto de mercúrio. Com certeza esse líquido se trata do $\mathrm{SnCl}_{4}$, conhecido a partir daí como spiritus fumans Libavii. ${ }^{3}$ Mas foi apenas no século XVIII que compostos inorgânicos de estanho começaram a ser estudados de forma mais profunda. Na primeira metade do século XIX o primeiro composto organoestânico, $\mathrm{SnEt}_{2} \mathrm{I}_{2}$, foi preparado por Sir Edward Frankland. ${ }^{6,7}$ Contudo, foi somente após a descoberta dos reagentes de Grignard e organolítios, dentre outros agentes alquilantes, que ocorreu um aumento do número de compostos inorgânicos e organometálicos de estanho. A descoberta das aplicações industriais do estanho foi fundamental para consolidar os compostos organoestânicos como uma importante área de pesquisa da química. Hoje, dentre os compostos organometálicos, os de estanho, titânio e alumínio são os mais consumidos em atividades industriais.

\section{ESTANHO NOS DIAS ATUAIS}

A cassiterita continua sendo hoje a principal fonte de estanho, sendo o mineral com o maior conteúdo associado de metal. Esse é obtido através de redução com carvão vegetal ou mineral em temperaturas que variam de 1100 a $1300^{\circ} \mathrm{C}$.

Todos os anos o Congresso dos Estados Unidos recebe relatórios dos Departamentos de Defesa e do Interior sobre as reservas americanas e mundiais de minerais, metais e de materiais considerados estratégicos para segurança aquele país, produção de energia e na manutenção das atividades industriais. ${ }^{8}$ Existe uma grande preocupação do governo com materiais cujas reservas americanas são escassas e/ou se encontram em outros países, aliados ou não, muitas vezes pouco confiáveis como aqueles onde não há segurança jurídica ou econômica, ou em lugares de disputas territoriais ou em guerra civil. Dentre esses metais aparece o estanho, que com certeza é um metal essencial para a economia americana, consequentemente para o mundo. Conclui-se então que o estanho é um dos poucos metais com marcas profundas no desenvolvimento da humanidade, desde sua infância até os dias atuais.

\section{ESTANHO NO BRASIL}

De acordo com um trabalho do início dos anos 2000, a primeira referência histórica sobre a cassiterita no Brasil diz respeito a uma Carta Régia de 28 de fevereiro de 1765, concedendo a Domingos Ferreira o direito de investigar a existência desse mineral na Comarca de São Paulo. ${ }^{9}$ Em relação à sua extração em território nacional, o registro mais antigo é de 1903, efetuado por garimpeiros de forma bastante rudimentar no rio Camaquã no município de Encruzilhada do Sul - RS. Somente no final da primeira metade do século XX é que se iniciou de forma mais acentuada a exploração brasileira, com a descoberta de depósitos de cassiterita em São João Del Rey MG e em Rondônia, cuja mecanização se deu apenas na década de
1970. ${ }^{9}$ O Brasil só se tornou importante no cenário internacional de comercialização de estanho na década de 1980, com a descoberta das maiores jazidas nacionais no Amazonas e Rondônia, respectivamente as minas do Pitinga e Bom Futuro

De acordo com dados de 2019 do Departamento de Defesa dos Estados Unidos, o Brasil possui uma reserva conhecida de cassiterita em torno de 700 mil toneladas. Em 2018 extraíram-se cerca de 18 mil toneladas, colocando nosso país na quarta posição mundial como produtor desse mineral, juntamente com Bolívia e Peru. ${ }^{8} \mathrm{~A}$ China ocupa o primeiro lugar com $36 \%$ da produção mundial de minério, a Indonésia aparece em segundo lugar, com $18 \%$ e a Birmânia ocupa a terceira posição com $11 \% .^{9}$

A maior parte das reservas brasileiras se localizam na região norte, Amazonas (mina do Pitinga) e Rondônia (minas de Santa Bárbara, Massangana, Cachoerinha e de Bom Futuro). A cassiterita é encontrada ainda em MG, Pará e São Paulo. A mina do Pitinga é explorada pela Mineração Taboca pertencente à mineradora peruana MINSUR, que controla cerca de $40 \%$ da produção brasileira, enquanto a mina de Santa Bárbara é da ERSA (Estanho de Rondônia S.A. sob controle da Companhia Siderúrgica Nacional). No ano de 2017, de acordo com o Anuário Mineral Brasileiro de 2018, a comercialização de cassiterita rendeu ao Brasil, cerca de 817 milhões de Reais, um aumento de $7 \%$ em relação ao ano anterior, representando $0,9 \%$ da comercialização brasileira de mineral bruto ou beneficiado, que em 2017 foi de pouco mais de 88 bilhões. ${ }^{9}$

Embora o Brasil esteja entre os grandes produtores de cassiterita, de acordo com os dados mais recentes fornecidos pelo Ministério das Minas e Energias, em 2017, 32\% da produção nacional de cassiterita foi destinada aos Estados Unidos da América. ${ }^{10}$ Mas, os principais fornecedores desse país ainda são Indonésia, Malásia, Peru e Bolívia. Apesar da balança comercial em relação ao estanho seja bastante positiva para o Brasil, ainda importamos estanho e derivados. Em 2015 , a despeito de ter ocorrido uma retração de $60 \%$ em relação ao ano anterior, foram US\$ 5,7 milhões gastos na compra de estanho na forma de pó, escamas, barras, fios e de compostos químicos. ${ }^{9} \mathrm{O}$ consumo nacional de estanho é da ordem de 4000 a 5000 t por ano, na forma de folhas de flandres, solda, produtos químicos, pewter (liga conhecida desde a antiguidade, composta de estanho, em quantidade que pode variar de 85 a 99\%, com cobre, antimônio e bismuto, sendo bastante empregada em peças decorativas) e bronze.

\section{A QUÍMICA DO ESTANHO}

Desde a descoberta do $\mathrm{SnEt}_{2} \mathrm{Cl}_{2}$ em 1849 por E. Frankland, a química do estanho tem atraído a atenção não só de químicos, mas de físicos, biólogos e de profissionais da área de novos materiais. Podem-se enumerar as diversas classes de compostos de estanho: os estananos, (i) $\mathrm{SnR}_{4}$, diestananos ou oligoestananos, (ii) $\left[\left(\mathrm{SnR}_{2}\right)_{\mathrm{n}}\right]$, (iii) estanatos, $\left[\mathrm{M}\left(\mathrm{SnR}_{3}\right)\right](\mathrm{M}=$ metal alcalino ou metais de transição), (iv) estanilenos $\left[\mathrm{SnR}_{2}\right]$ ( $\mathrm{R}$ = grupo orgânico volumoso), (v) estanocenos $\left[\mathrm{SnCp}_{2}\right]$, (vi) estanenos $\left[\mathrm{R}_{2} \mathrm{Sn}=\mathrm{SnR}_{2}\right](\mathrm{R}=$ grupo orgânico bastante volumoso), semelhantes aos alquenos, os (vii) estaninos [RSn $\equiv \mathrm{SnR}](\mathrm{R}=$ grupo orgânico hiper volumoso), análogos aos alquinos. ${ }^{11-18} \mathrm{O}$ estado de oxidação +4 é o mais comum do estanho na maioria de seus compostos, enquanto o +2 é mais escasso, presente em estanatos, estanilenos, estanocenos e em alguns polímeros de coordenação. Estados de oxidação +3 ou +1 são muito raros. Existem ainda compostos com o metal em estados de oxidação negativos, como em íons de Zintl, $\mathrm{Na}_{4}\left[\mathrm{Sn}_{9}\right] .{ }^{19,20}$

Salientou-se anteriormente a importância dos reagentes orgânicos de lítio e Grignard no desenvolvimento da química do estanho, mas deve-se ressaltar também o papel de técnicas de caracterização como difração de raios-X, espectroscopia de RMN de ${ }^{117} \mathrm{Sn}$ e de 
${ }^{119} \mathrm{Sn}$, em solução e no estado sólido, e espectroscopia de Mössbauer de ${ }^{119} \mathrm{Sn}$, que trouxeram consequências positivas para essa química, possibilitando a obtenção de importantes informações estruturais. ${ }^{21,22}$ Em sentido inverso, o estudo da química do estanho permite que pesquisadores e estudantes se familiarizem com as potencialidades dessas técnicas espectroscópicas. ${ }^{23}$

\section{A química do cátion $\mathrm{Sn}(\mathrm{II})$}

Em comparação ao $\mathrm{Sn}(\mathrm{IV})$, a química do $\mathrm{Sn}$ (II) é menos comum, devido à dificuldades de manipulação, já que este cátion exibe alta sensibilidade à umidade e oxigênio. ${ }^{24}$ Mas curiosamente, na última década surgiram alguns polímeros de coordenação de $\mathrm{Sn}$ (II) com alta estabilidade química e térmica, contrariando a tendência observada nos primeiro compostos de $\mathrm{Sn}$ (II) sintetizados anos antes. ${ }^{25}$

Dentre os compostos de $\mathrm{Sn}(\mathrm{II})$ destacam-se os estanilenos, [ $\left.\mathrm{SnR}_{2}\right]$, os estanocenos, $\left[\mathrm{SnCp}_{2}\right]$, os estanatos metálicos, $\left[\mathrm{MSnR}_{3}\right]$ e alguns polímeros de coordenação. ${ }^{26,27}$

\section{Estanilenos}

Os estanilenos são análogos aos carbenos, cuja estrutura molecular monomérica ou polimérica dependerá da natureza do grupo R. Se for volumoso ocorrerá a formação de monômero ou dímeros, caso contrário polímeros, $\left(-\mathrm{SnR}_{2}-\mathrm{SnR}_{2}-\mathrm{SnR}_{2}-\right)_{n}$. Outra questão que precisa ser comentada é que essa classe de compostos de $\mathrm{Sn}(\mathrm{II})$ agrupa não só espécies contendo ligações químicas $\sigma$ do tipo Sn-C, mas também compostos com ligações Sn-N, Sn-O, etc. $\left.\mathrm{O}\left[\left\{\left(\mathrm{Me}_{3} \mathrm{Si}\right)_{2} \mathrm{CH}\right\}_{2} \mathrm{Sn}-\mathrm{Sn}\left\{\mathrm{CH}\left(\mathrm{SiMe}_{3}\right)_{2}\right\}_{2}\right)\right]$, foi o primeiro exemplo de estanileno isolado no início dos anos de 1970 e caracterizado por difração de raios-X. ${ }^{28}$ Esse complexo é dimérico no estado sólido e monomérico em solução ou no estado gasoso. ${ }^{29} \mathrm{~A}$ natureza da ligação química $\mathrm{Sn}$-Sn foi estudada por muitos anos, especulando-se se seria uma ligação dupla entre metais representativos ou algum outro tipo de ligação química ainda não descrita.

Nos anos subsequentes vários exemplos de estanilenos surgiram na literatura, Tabela 1. Dentre os exemplos mais interessantes destaca-se a espécie heterometálica $\left[\mathrm{Sn}\left\{\mu-\left(\mathrm{NBu}^{\mathrm{t}}\right)_{2} \mathrm{~W}\left(\mathrm{NBu}^{\mathrm{t}}\right)_{2}\right\}_{2}\right]$, onde o $\mathrm{W}(\mathrm{VI})$ forma ligações duplas com os nitrogênios terminais, Figura $2 .{ }^{30}$

\section{Derivados ciclopentadienílicos}

O Sn(II) se liga a anéis ciclopentadienílicos (Cp) através de ligação $\pi$, por analogia ao ferroceno eles são denominados de estanocenos. Suas propriedades estruturais e estabilidade dependem fortemente da natureza do grupo $\mathrm{Cp}$. Todos eles são sensíveis à umidade e ao ar, exceto $\left[\mathrm{Sn}\left(\eta^{5}-\mathrm{C}_{5} \mathrm{Ph}_{5}\right)_{2}\right],\left[\operatorname{Sn}\left(\eta^{5}-\mathrm{C}_{5} \mathrm{Bz}_{5}\right)_{2}\right],\left[\operatorname{Sn}\left(\eta^{5}-\mathrm{C}_{5} \mathrm{Pr}_{4}{ }_{4} \mathrm{H}\right)_{2}\right]$ e $\left[\mathrm{Sn}\left(\eta^{5}-\mathrm{Cp}^{\mathrm{S}}\right)_{2}\right] \cdot{ }^{31-33} \mathrm{Na}$ maioria dos estanocenos os anéis carbônicos

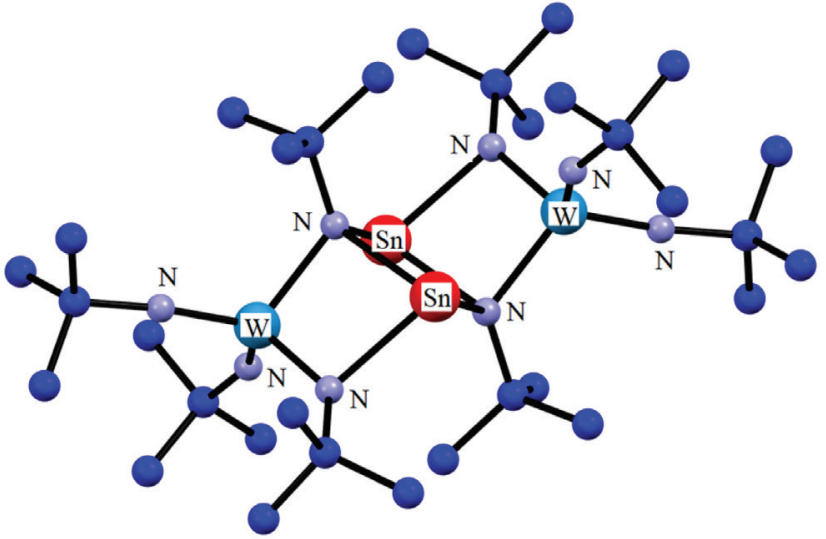

Figura 2. Estrutura molecular do [Sn $\left.\left\{\mu-\left(N B u^{t}\right)_{2} W\left(N B u^{t}\right)_{2}\right\}_{2}\right]$. A figura foi produzida utilizando-se os arquivos CIFs obtidos do CCDC (https://www. ccdc.cam.ac.uk/) cuja licença é mantida pela CAPES

se apresentam de forma não-paralela, $\left[\mathrm{Sn}\left(\eta^{5}-\mathrm{C}_{5} \mathrm{H}_{5}\right)_{2}\right]$, mas existem exemplos que fogem a essa tendência. Os anéis ciclopentadienílicos no $\left[\mathrm{Sn}\left(\eta^{5}-\mathrm{C}_{5} \mathrm{Me}_{5}\right)_{2}\right]$ são paralelos, tornando o par não ligante do $\mathrm{Sn}(\mathrm{II})$ estereoquimicamente inativo, Figura $3 .^{34}$
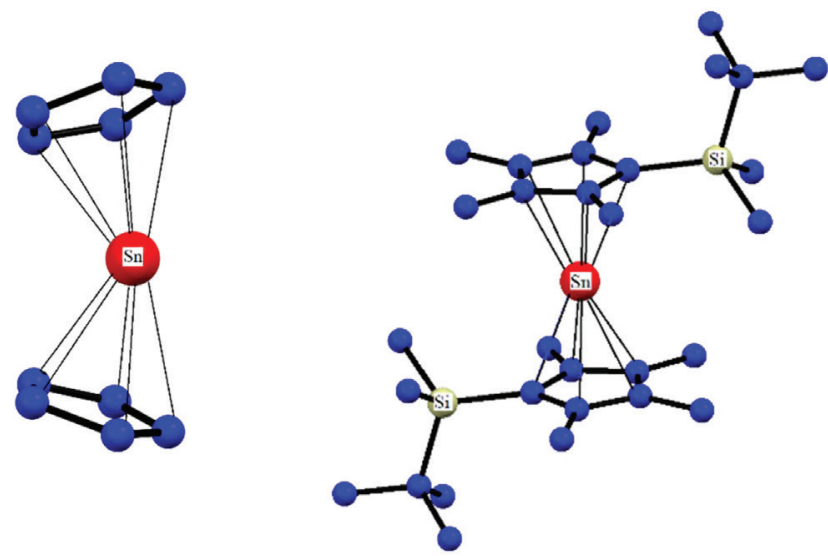

Figura 3. Estrutura molecular do $\left[\mathrm{Sn}\left(\eta^{5}-\mathrm{C}_{5} \mathrm{H}_{5}\right)_{2}\right]$ e do $\left[\mathrm{Sn}\left(\eta^{5}-\mathrm{Cp}^{S}\right)_{2}\right]$. ]. A figura foi produzida utilizando-se os arquivos CIFs obtidos do CCDC (https://www. ccdc.cam.ac.uk/) cuja licença é mantida pela CAPES

Um dos exemplos mais interessantes é o $\left[\mathrm{Sn}\left\{\eta^{5}-\left(\mathrm{Cp}^{\mathrm{B}}\right) \mathrm{Co}\left(\mathrm{C}_{5} \mathrm{H}_{5}\right)\right\}_{2}\right]$, espécie heterometálica que enriquece não só a química do estanho, mas também do boro e do cobalto, Figura $4 .{ }^{35}$

Tabela 1. Alguns exemplos de estanilenos

\begin{tabular}{|c|c|c|c|}
\hline Composto & Ref & Composto & Ref. \\
\hline$\left[\left(\mathrm{Sn}\left\{\mathrm{CH}\left(\mathrm{SiMe}_{3}\right)_{2}\right\}_{2}\right)_{2}\right]$ & 24 & {$\left[\left\{4-\mathrm{Bu}^{\mathrm{t}}-2,6-\left\{\mathrm{O}=\mathrm{P}\left(\mathrm{OPri}^{\mathrm{i}}\right)_{2}\right\}_{2} \mathrm{C}_{6} \mathrm{H}_{2} \mathrm{Sn}\right\} \mathrm{C}_{5} \mathrm{H}_{4}\right]_{2} \mathrm{Fe}$} & 24 \\
\hline$\left[\left(\mathrm{Sn}\left\{\mathrm{Si}\left(\mathrm{SiMe}_{3}\right)_{3}\right\}_{2}\right)_{2}\right]$ & 24 & {$\left[\left\{4-\mathrm{Bu}^{\mathrm{t}}-2,6-\left\{\mathrm{O}=\mathrm{P}\left(\mathrm{OPr}^{\mathrm{i}}\right)_{2}\right\}_{2} \mathrm{C}_{6} \mathrm{H}_{2} \mathrm{Sn}-\mathrm{W}(\mathrm{CO})_{5}\right\} \mathrm{C}_{5} \mathrm{H}_{4}\right]_{2} \mathrm{Fe}$} & 24 \\
\hline$\left[\left(\mathrm{Sn}\left\{\mathrm{C}_{6} \mathrm{H}\left(\mathrm{Bu}^{\mathrm{t}}-2\right)\left(\mathrm{Me}_{3}-4,5,6\right)\right\}_{2}\right)_{2}\right]$ & 24 & {$\left[\left\{4-\mathrm{Bu}^{\mathrm{t}}-2,6-\left\{\mathrm{O}=\mathrm{P}\left(\mathrm{OPr}^{\mathrm{i}}\right)_{2}\right\}_{2} \mathrm{C}_{6} \mathrm{H}_{2} \mathrm{Sn}\right\} \mathrm{C}_{5} \mathrm{H}_{4}\right]_{2} \mathrm{Fe} \cdot \mathrm{Cr}(\mathrm{CO})_{4}$} & 24 \\
\hline$\left[\mathrm{Sn}\left\{\mathrm{C}\left(\mathrm{SiMe}_{3}\right)_{2} \mathrm{C}_{5} \mathrm{H}_{4} \mathrm{~N}-2\right\}_{2}\right]$ & 24 & $\mathrm{~K}(\mathrm{thf})_{6}[\mathrm{ArSn} \equiv \mathrm{SnAr}]$ & 24 \\
\hline$\left[\mathrm{Sn}\left\{\mathrm{C}_{10} \mathrm{H}_{6} \mathrm{~N}(\mathrm{Me}-8)_{2}\right\}_{2}\right]$ & 24 & {$\left[\mathrm{Sn}\left\{\mathrm{N}\left(\mathrm{SiMe}_{3}\right)_{2}\right\}_{2}\right]$} & 24 \\
\hline$\left[\mathrm{Sn}\left\{\mathrm{C}_{6} \mathrm{H}_{2}\left(\mathrm{CF}_{3}\right)_{3}-2,4,6\right\}_{2}\right]$ & 24 & {$\left[\mathrm{Sn}\left\{\mathrm{NCMe}_{2}\left(\mathrm{CH}_{2}\right)_{3} \mathrm{CMe}_{2}\right]_{2}\right.$} & 24 \\
\hline$\left[\left(\mathrm{Sn}\left\{\mathrm{C}_{6} \mathrm{H}_{2}\left(\mathrm{CF}_{3}\right)_{3}-2,4,6\right\}_{2}\right)_{2}\right]$ & 24 & {$\left[\mathrm{Sn}\left\{\mathrm{NH}\left(2,4,6 \text {-tris- } \mathrm{Bu}^{\mathrm{t}-} \mathrm{C}_{6} \mathrm{H}_{2}\right)\right\}_{2}\right]$} & 24 \\
\hline$\left[\mathrm{Sn}\left(\mathrm{C}_{6} \mathrm{H}_{2} \mathrm{Pr}_{3}^{\mathrm{i}}-2,4,6\right)_{2}\right]$ & 24 & {$\left[\mathrm{Sn}\left\{\mu-\left(\mathrm{NBu}^{\mathrm{t}}\right)_{2} \mathrm{SiMe}_{2}\right\}\right]$} & 24 \\
\hline$\left[\mathrm{Sn}\left(\mathrm{C}_{6} \mathrm{H}_{2} \mathrm{Bu}_{3}^{\mathrm{t}}-2,4,6\right)_{2}\right]$ & 24 & {$\left[\mathrm{Sn}\left\{\mu-\left(\mathrm{NSiMe}_{3}\right)_{2} \mathrm{PPh}_{2}\right\}_{2}\right]$} & 24 \\
\hline$\left[\mathrm{SnC}\left(\mathrm{SiMe}_{3}\right)_{2}\left(\mathrm{CH}_{2}\right)_{2} \mathrm{C}\left(\mathrm{SiMe}_{3}\right)_{2}\right]$ & 24 & {$\left[\mathrm{Sn}\left\{\mu-\left(\mathrm{NBu}^{\mathrm{t}}\right)_{2} \mathrm{~W}\left(\mathrm{NBu}^{\mathrm{t}}\right)_{2}\right\}_{2}\right]$} & 24 \\
\hline
\end{tabular}




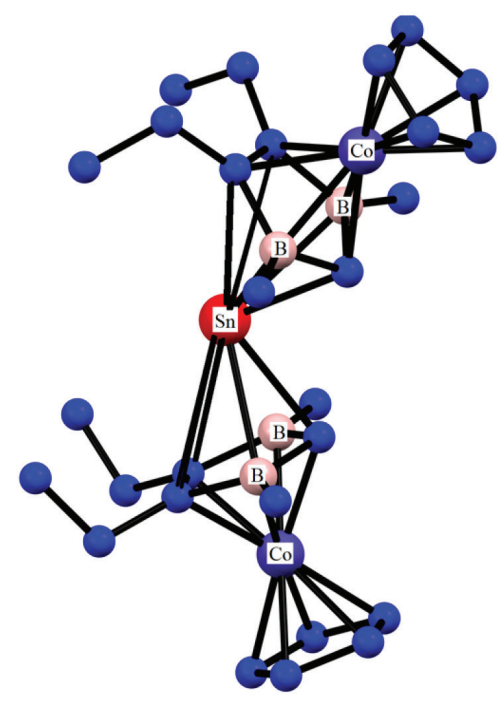

Figura 4. Estrutura molecular de $\left[\mathrm{Sn}\left\{\eta^{5}-\left(\mathrm{Cp}^{B}\right) \mathrm{Co}\left(\mathrm{C}_{5} \mathrm{H}_{5}\right)\right\}_{2}\right]$. A figura foi produzida utilizando-se os arquivos CIFs obtidos do CCDC (https://www. ccdc.cam.ac.uk/) cuja licença é mantida pela CAPES

Estanocenos podem gerar outras espécies químicas, abrindo um horizonte vasto de possibilidades de reações subsequentes, por exemplo [ $\left.\mathrm{Sn}\left(\eta^{5}-\mathrm{Cp}\right) \mathrm{Cl}\right],\left[\mathrm{Sn}\left(\eta^{5}-\mathrm{Cp}\right) \mathrm{BF}_{4}\right]$ e $\left[\mathrm{Sn}\left(\eta^{5}-\mathrm{Cp}\right) \mathrm{OSO}_{2} \mathrm{CF}_{3}\right]$, ou compostos análogos com diferentes anéis $\mathrm{Cp}$, que são geralmente obtidos ao se reagir um estanoceno com $\mathrm{HCl}, \mathrm{HBF}_{4}$ ou $\mathrm{HOSO}_{2} \mathrm{CF}_{3}$. Reação subsequente do derivado $\mathrm{Sn}\left(\eta^{5}-\mathrm{Cp}^{\mathrm{S}}\right) \mathrm{Cl}$ com $\mathrm{SnCl}_{2}$ em thf levou à formação de uma espécie poli-iônica de formulação $\left[\mathrm{Sn}_{9}\left(\eta^{5}-\mathrm{Cp}^{\mathrm{S}}\right)_{6} \mathrm{Cl}_{12}\right] \cdot{ }^{36,37}$

\section{Estanatos metálicos}

Durante muitos anos estanatos de metais alcalinos ou alcalino terrosos foram considerados espécies fugazes, geradas apenas in situ, como fonte de ânions ${ }^{-} \mathrm{SnR}_{3}$. Espécies químicas desse tipo são bastante conhecidas por formarem diversas ligações do tipo Sn-M ou $\mathrm{Sn}-\mathrm{C}$. Em décadas passadas surgiu um grande interesse no isolamento desses ânions principalmente para se estabelecer o grau de covalência da ligação entre o estanho e outros metais, se essas espécies seriam descritas como $\mathrm{MSnR}_{3},\left[\mathrm{M}^{+}\right]\left[\mathrm{SnR}_{3}\right]$ ou um misto de ambas as representações. Dessa forma vários exemplos foram caracterizados por cristalografia de raios-X, Tabela 2.

Além da caracterização estrutural, tornam-se imprescindíveis experimentos de RMN de vários núcleos em solução e no estado sólido, principalmente envolvendo núcleos ativos no RMN, de forma a determinar a constante de acoplamento ${ }^{1} \mathrm{~J}_{\mathrm{Sn}-\mathrm{M}}$, uma medida bastante precisa do grau de covalência da ligação Sn-M. Estanatos de metais de transição, $\mathrm{MSnR}_{3}$ são mais numerosos, existem depositadas no CCDC (Cambridge Crystallographic Data Centre) cerca de 420 estruturas. $^{51}$
Polímeros de coordenação

Polímeros de coordenação são materiais formados pela coordenação de cátions metálicos espaçados por ligantes orgânicos, sendo carboxilatos os mais populares. Dentre esses polímeros de coordenação destacam-se os agregados metalo-orgânicos, denominados em inglês por MOFs (metal-organic framework). Além das novas características estruturais, salientam-se as potenciais aplicações em catálise, armazenamento de gases, como hidrogênio e $\mathrm{CO}_{2}$, dentre outros usos. ${ }^{52-55} \mathrm{~A}$ grande maioria desses materiais relatados na literatura são construídos utilizando-se metais de transição, especialmente aqueles do primeiro período. Em relação ao grupo 14 da tabela periódica existem algumas estruturas contendo $\mathrm{Pb}(\mathrm{II})$, mas os de $\mathrm{Sn}$ (II) são escassos, exceto alguns polímeros contendo oxalato como ligante. Nesses poucos exemplares de $\mathrm{Sn}(\mathrm{II})$, seu par eletrônico não ligante desempenha um papel importante no direcionamento da dimensionalidade do polímero, 1D, 2D ou 3D. Em relação ao Sn(IV), existem raríssimos exemplos de polímeros de coordenação, à despeito da habilidade desse cátion formar polioxometalatos ou de se coordenar a ligantes polibásicos, formando complexos moleculares. ${ }^{56,57}$ Recentemente alguns exemplos interessantes de polímeros de coordenação de $\mathrm{Sn}$ (II) enriqueceram a química desse cátion, sintetizados através de reações hidrotérmicas em meio alcalino, entre ácidos carboxílicos e $\mathrm{SnSO}_{4} \cdot{ }^{25}$

\section{A química do cátion $\operatorname{Sn}(I V)$}

Compostos de $\mathrm{Sn}(\mathrm{IV})$ são representados por $\mathrm{SnX}_{4}$ ou $\mathrm{SnR}_{\mathrm{y}} \mathrm{X}_{(4-\mathrm{y})}$ (onde $\mathrm{R}$ representa grupos orgânicos de qualquer tipo, $\mathrm{X}$ simboliza halogênios ou pseudo halogênios). Além desses compostos existem ainda aqueles resultantes de reações ácido/base de Lewis com ligantes iônicos, carboxilatos, ditiocarbamatos, ditiocarbimatos, dentre outros, ou com ligantes neutros. A variedade desses compostos tem sido revista na literatura de tempos em tempos, onde se tenta agrupar esses compostos de acordo com características estruturais e de potenciais aplicações. ${ }^{58-64}$

\section{ALGUMAS APLICAÇÕES DO ESTANHO}

Além do bronze, o estanho foi bastante utilizado na fabricação de latas para acondicionar alimento. A principal motivação no início foi encontrar uma logística eficiente de se oferecer alimentação rápida a combatentes em movimento. Então, no final do século XVIII Napoleão Bonaparte ofereceu 12 mil francos para quem propusesse potenciais soluções dessa questão militar. Em 1810 Nicolas Appert ganhou essa recompensa por inventar o processo de conservação de comida em jarras de vidro. ${ }^{65}$ Quase imediatamente o comerciante Britânico Peter Durand registrou uma patente de uso de latas de aço com uma fina camada de estanho, produzindo já em 1813 comida enlatada para a Marinha Britânica. ${ }^{66} \mathrm{Um}$ dos erros iniciais foi fechar a tampa das latas com uma solda feita de estanho e chumbo.

Tabela 2. Alguns exemplos de estanatos de metais alcalino e alcalino terrosos

\begin{tabular}{|c|c|c|c|}
\hline Composto & ref & Composto & ref \\
\hline$\left[\mathrm{Li}(\right.$ pmdeta $\left.) \mathrm{SnPh}_{3}\right]$ & 38 & {$\left[\left\{\mathrm{Na}(\mathrm{pz})(\mathrm{thf})(\mu-\mathrm{pz})_{2} \mathrm{Sn}(\mathrm{pz})\right\}_{2}\right]$} & 39 \\
\hline $\mathrm{Li}(\mathrm{hmpa}) \mathrm{SnBu}_{3}{ }_{3}$ & 40 & {$\left[\mathrm{~K}\left(18\right.\right.$-crown-6) $\left.\mathrm{SnPh}_{3}\right]$} & 41 \\
\hline$\left[\mathrm{Li}(\operatorname{thf})\left\{\mathrm{Sn}\left(\mu-\mathrm{PBu}_{2}^{\mathrm{t}}\right)_{2}\left(\mathrm{PBu}_{2}^{\mathrm{t}}\right)\right\}\right]$ & 42 & {$\left[\mathrm{~K}(\mathrm{dme})_{2} \mathrm{Sn}\left(\mu-\mathrm{OSiPh}_{3}\right)_{3}\right]$} & 43 \\
\hline$\left[\mathrm{Li}(\text { thf })_{3}(\mu-\mathrm{Cl}) \mathrm{Sn}\left(\mathrm{Si}\left\{\mathrm{SiMe}_{3}\right)_{3}\right\}_{2}\right]$ & 44 & {$\left[\mathrm{~K}(\eta \text {-toluene })_{3} \mathrm{Sn}(\mathrm{Np})_{3}\right]$} & 45 \\
\hline$\left[\mathrm{Sn}\left(\eta-\mathrm{C}_{5} \mathrm{H}_{5}\right)\left\{\mathrm{N}\left(\mathrm{SiMe}_{3}\right)_{2}\right\}\left(\mu-\eta-\mathrm{C}_{5} \mathrm{H}_{5}\right)\right.$ Li(pmdeta) $]$ & 46 & {$\left[\mathrm{Ca}(\text { thf })_{4}\left(\mathrm{SnMe}_{3}\right)_{2}\right]$} & 47 \\
\hline$\left[\left\{\mathrm{Li}(\text { thf })_{4}\right\}\left\{\mathrm{Sn}\left(\mathrm{C}_{13} \mathrm{H}_{9}\right)_{3}\right\}\right.$ & 48 & {$\left[\mathrm{Ca}\left\{\mathrm{Sn}\left(\mu-\mathrm{OSiMe}_{2} \mathrm{Bu}^{\mathrm{t}}\right)_{3}\right\}_{2}\right]$} & 49 \\
\hline$\left[\mathrm{Sn}\left(\eta-\mathrm{C}_{5} \mathrm{H}_{5}\right)_{3} \mathrm{Na}(\right.$ pmdeta $\left.)\right]$ & 50 & & \\
\hline
\end{tabular}

Pmdeta = N,N,N',N",N"-Pentametildietilenetriamina; hmpa: Hexametilfosforamida; dme: dimetoxietano; thf tetrahidrofurano; pz: pirazol; Np: neopentila. 
As consequências foram imediatas, suspeita-se que os membros da expedição de Sir J. Franklin ao Ártico tenham sido envenenados com chumbo proveniente das latas de alimento. Em 1818 esse processo de conservação de alimento chegou aos Estados Unidos, tornando-se bastante popular durante a guerra civil. No final da primeira metade do século XX o alumínio, mais leve e reciclável começou a substituir parcialmente as latas de aço revestidas com estanho. ${ }^{67}$ Estudos da década de 1960 revelaram que alimentos com características ácidas podem remover parte desse revestimento, levando à lixiviação do estanho. ${ }^{68}$ Embora tenha sido detectado no alimento, é bastante provável que ele se encontre na forma de $\mathrm{SnO}_{2}$, completamente inerte e atóxico. Certamente, pesquisas suplementares poderão demonstrar a segurança alimentar desse processo de conservação utilizado durante décadas.

Nos dias de hoje o estanho é empregado na fabricação de folhas de flandres, soldas, pewter, produtos químicos, bronze, dentre outras aplicações de menor importância. Folhas de aço são recobertas com uma fina camada de estanho na proporção de $4 \mathrm{~kg}$ desse metal para cada tonelada de aço, formando o que se chama de folhas de flandres, tornando o aço mais resistente à corrosão.

Devido ao baixo ponto de fusão e grande tendência em formar ligas com outros metais, o estanho é usado em soldas, aplicação que vem demandado quantidades crescentes do metal, devido a soldagem de dispositivos eletrônicos.

Com o surgimento do estanho eletrolítico e com o desenvolvimento da química do estanho, novas aplicações foram descobertas, tais como na fabricação de tintas anti-incrustantes, agentes biocidas, em catálise, bem como na fabricação de painéis de celulares, computadores e de televisores, sensíveis ao toque, o que ampliou a demanda mundial por estanho.

\section{Organoestânicos como agentes biocidas}

Os ligantes mais investigados associados ao Sn(IV) ou a fragmentos organoestânicos são os carboxilatos, ditiocarbamatos, ditiocarbimatos, semicarbazonas, tiossemicarbazonas, dentre outros. Vários relatos documentados na literatura registram possíveis aplicações de complexos organoestânicos como agentes antimicrobianos, antitumorais, antifúngicos, antimaláricos e anti-inflamatórios. ${ }^{69-78} \mathrm{Em}$ contrapartida outros artigos enfatizam alguns aspectos prejudiciais dos organoestânicos, tais como os efeitos citotóxicos, genotóxicos, mutagénicos e neurotóxico. ${ }^{79}$ Apesar desses aspectos negativos, têm-se estudado os possíveis mecanismos de ação e os resultados de dose-resposta, bastante necessários caso se queira explorar os efeitos terapêuticos dessa classe de compostos e de seus complexos de coordenação. A maior parte dos artigos publicados, além de descreverem as sínteses e caracterizações de novos complexos, relatam suas atividades antimicrobianas. A literatura científica é ainda pobre no que diz respeito ao conhecimento dos respectivos mecanismos de ação, ou de estudos relacionando as atividades biológicas com as estruturas dos complexos.

Um dos trabalhos pioneiros foi feito com células de levedura Candida albicans, ATCC 18804. Os complexos utilizados, (1) - (3) derivados do ácido aminobenzóico com os fragmentos $\mathrm{SnMe}_{2} \mathrm{e}$ $\mathrm{SnBu}_{2}$, Figura 5, inibiram o crescimento do fungo, sendo seus valores de $\mathrm{IC}_{50}$ comparáveis aos dos produtos comerciais miconazol, anfotericina e fluconazol. ${ }^{80}$

Nesse estudo avaliou-se a integridade do DNA após crescimento do fungo na presença dos complexos. Além disso, o estudo de viabilidade celular mostrou que os agentes externos não comprometeram a função respiratória da levedura. Observou-se ainda a possível interferência dos complexos na biossíntese da molécula de ergosterol, espécie responsável pela integridade da membrana que reveste a célula. Finalmente a morfologia das células foi avaliada por<smiles>COC(=O)c1ccccc1NCc1ccccc1OC</smiles>

(1)
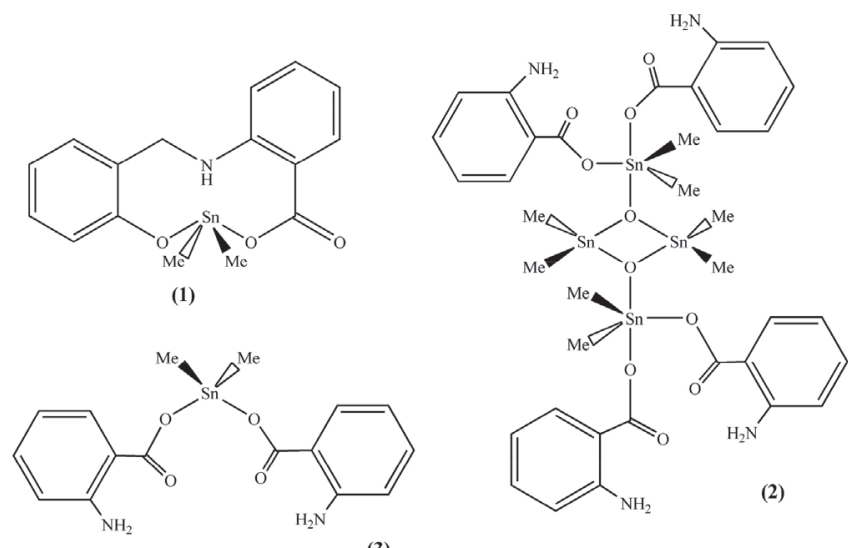

(3)
Figura 5. Estrutura dos complexos [N-(2-carboxifenil)salicilideneiminato] dimetilestanho(IV), (1), bis $\left(\mu_{3}\right.$-O-aminobenzoato-O, $\left.O^{\prime}\right)$ bis $(O$-aminobenzoato)tetrakis[dimetilestanho(IV)], (2) e bis(O-aminobenzoato-O, $\left.O^{\prime}\right)$ di-n-butilestanho(IV), (3)

microscopia eletrônica de transmissão (MET) durante a exposição do microrganismo aos complexos organoestânicos.

Em outro estudo, realizado por Ahmad e colaboradores (2011) investigou-se a atividade antifúngica de um polímero organoestânico, frente a cinquenta e nove isolados de Candida e tendo como controle o fluconazol. Medidas da concentração da molécula de ergosterol indicou que o composto de estanho apresenta um modo de ação semelhante ao do fluconazol. Nath e colaboradores estudaram a atividade antitumoral in vitro de complexos tri- e diorganoestânicos derivados do ácido orótico $\left(\mathrm{H}_{3} \mathrm{Or}\right.$, vitamina $\left.\mathrm{B} 13\right)$, de formulação $\mathrm{R}_{\mathrm{n}} \mathrm{Sn}\left(\mathrm{H}_{2} \mathrm{Or}\right)_{\mathrm{m}}(\mathrm{n}=2,3 ; \mathrm{m}=1,2 ; \mathrm{R}=\mathrm{Me}, \mathrm{Bu}, \mathrm{Oc}$ e Ph) frente a linhagens de células humanas como câncer de mama, rins, próstata, fígado e cólon. ${ }^{81,82}$ Nesse trabalho um estudo da ação do complexo mais ativo, o $\mathrm{SnOc}_{2}\left(\mathrm{H}_{2} \mathrm{Or}\right)_{2}$ frente a diferentes enzimas, tais como, lactato desidrogenase (LDH), glutationa redutase (GR), glutationa peroxidase (GPx), glutationa total (GT) e peroxidação lipídica (PL). Ensaios de fragmentação do DNA mostraram que esses complexos induzem a morte celular por apoptose.

Por meio de cálculos teóricos é possível obter os parâmetros estruturais e estéreo-eletrônicos que servem de suporte para o estudo de mecanismos promissores relacionados com o transporte de cada composto através das membranas celulares e possíveis interações com macromoléculas biológicas. ${ }^{83}$

\section{Organoestânicos como estabilizantes do policloreto de vinila (PVC)}

PVC é um dos materiais mais utilizados no mundo, seja na forma de plásticos rígidos ou flexíveis, ocupando a terceira posição depois do polietileno e do polipropileno, Figura 6. Cerca de 30 milhões de toneladas desse material são consumidas anualmente no mundo. Para produzir tudo isso são necessárias 75 mil toneladas de compostos organoestânicos, adicionados como estabilizantes no processo. Estabilizantes são incorporados ao PVC com a finalidade de evitar ou retardar a degradação do polímero, por aumento da temperatura ambiente e/ou prolongada exposição a fontes de radiação, como UV do sol.

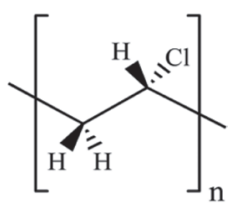

Figura 6. Estrutura do policloreto de vinila, $P V C$ 
A literatura mostra que o alvo dos estabilizantes no PVC é o íon cloreto, que ao ser capturado, evita a desidrocloração e consequentemente a degradação do polímero, Figura 7.

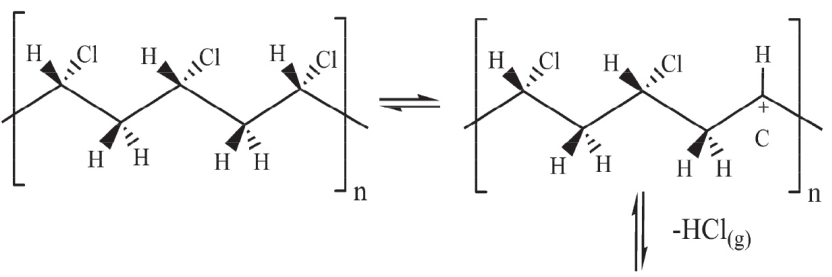

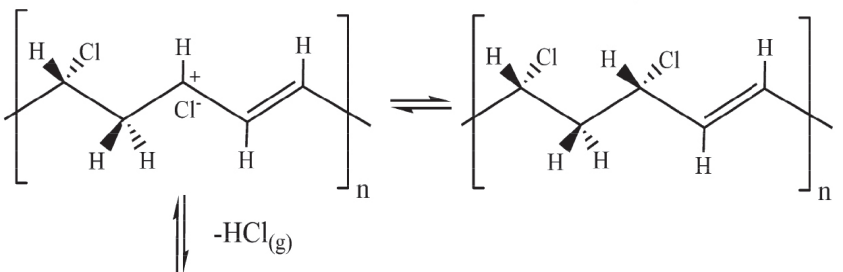<smiles>CC(C)/C=C/C=C/C12CCC1(C)C2</smiles>

Figura 7. Mecanismo de desidrocloração do PVC

Os primeiros compostos organoestânicos adicionados ao PVC foram o laurato de dibutilestanho e em seguida o maleato de dibutilestanho introduzidos pela empresa Union Carbide na década de 1930, Figura 8.

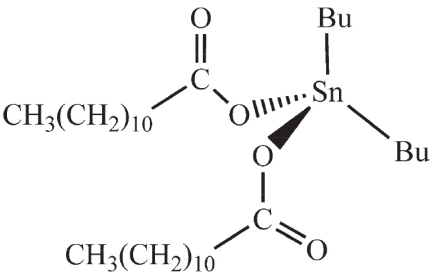<smiles></smiles>

Laurato de dibutilestanho

Maleato de dibutilestanho

Figura 8. Estruturas do laurato de dibutilestanho e do maleato de dibutilestanho

Já no final da década de 1940 a Firestone desenvolveu tiolatos organoestânicos $\mathrm{SnR}_{2}\left(\mathrm{SR}^{\prime}\right)_{2}$ que possuem alta compatibilidade com o PVC, mas, devido ao cheiro característico, esses compostos restringiram a variedade de aplicações desse tipo de PVC, não sendo utilizado, por exemplo, em embalagens de alimentos e fármacos. ${ }^{84} \mathrm{De}$ forma geral os compostos mais utilizados como estabilizantes são os do tipo $\mathrm{SnR}_{2} \mathrm{X}_{2}\{\mathrm{R}=\mathrm{Me}, \mathrm{Bu}, \mathrm{Oc}$, etc; $\mathrm{X}=$ carboxilatos, tiolatos, etc $\}$.

A adição de compostos organoestânicos, ou de outros cátions metálicos tem como objetivo impedir a ação do $\mathrm{HCl}$ no primeiro estágio da degradação. Ao entrar em contato com o $\mathrm{HCl}$ ocorrerá a formação do haleto correspondente, evitando a evolução desse processo que poderá afetar o desempenho eficaz e funcional do polímero. São vários os mecanismos pelos quais os carboxilatos organoestânicos estabilizam o PVC. Eles podem por exemplo, sequestrar o $\mathrm{HCl}_{(\mathrm{g})}$ levando à formação do haleto organoestânico e do ácido carboxílico correspondente, Figura 9.

Eles podem também se coordenar ao átomo de cloro na superfície do polímero, estabilizando-o e consequentemente evitando o início da etapa de desidrocloração.

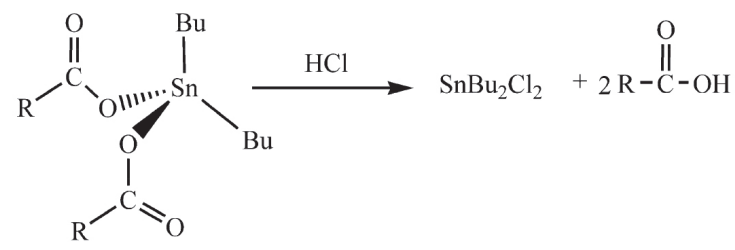

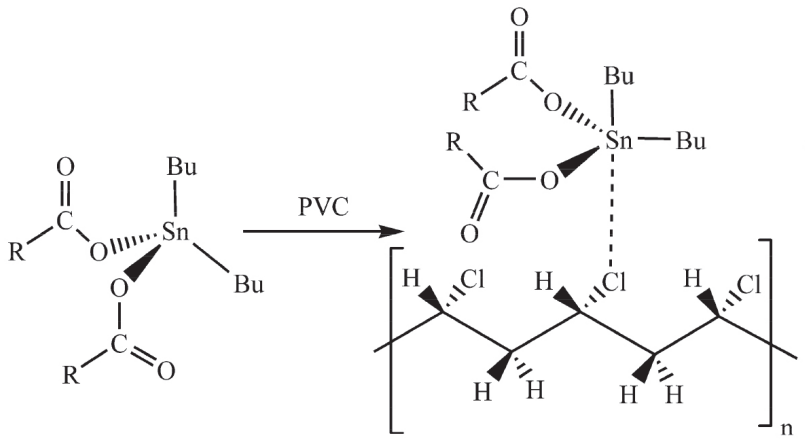

Figura 9. Alguns dos mecanismos pelos quais carboxilatos organoestânicos atuam como estabilizantes do PVC

\section{Organoestânicos utilizados em catálise}

A maior aplicação em larga escala de compostos organoestânicos é em catálise. Dentre os processos mais importantes destacam-se a produção de poliuretano, vulcanização de silicones e reações de transesterificação. A seguir descrevem-se dois desses processos.

\section{Produção de poliuretano}

Poliuretano é um tipo de espuma cuja rigidez ou flexibilidade dependerá dos grupos químicos presentes em sua estrutura. É utilizado numa grande variedade de aplicações, por exemplo em moldagens, na produção de fibras, materiais adesivos, isolantes térmicos e acústicos em residências, fabricação de colchões, pneus e roupas (poliésteres), preenchimentos de objetos tais como refrigeradores, partes de automóveis, sapatos, etc. Em 2018 foram produzidos no mundo em torno de 21 milhões de toneladas, sendo China e EUA os maiores produtores e consumidores. ${ }^{85}$ Os dados mais recentes do Brasil referem-se a 2015, ano em que se produziram 620 mil toneladas, rendendo 112 milhões de dólares e permitindo que nosso país ocupasse a $8^{\text {a }}$ posição no mundo na produção de poliuretano. ${ }^{86}$

O poliuretano é preparado através da reação entre uma molécula contendo dois ou mais grupos diisocianato e um poliol, contendo duas ou mais hidroxilas, na presença de um catalisador ou de luz UV, Figura 10.

Compostos diorganoestânicos são normalmente utilizados como catalisadores nessa reação. Alguns mecanismos são propostos para descrever sua atuação catalítica, segue abaixo um deles, Figura 11.

De acordo com o mecanismo apresentado na Figura 11, o haleto diorganoestânico reage inicialmente com o álcool formando $\mathrm{R}_{2} \mathrm{SnXOR}$ ou $\mathrm{R}_{2} \mathrm{Sn}\left(\mathrm{OR}^{\prime}\right)_{2}$. Em seguida o isocianato se insere na ligação $\mathrm{Sn}-\mathrm{O}$, produzindo um carbamato, onde o fragmento organoestânico se coordena ao átomo de nitrogênio. Na etapa seguinte ocorre a liberação do uretano e nova reação com o álcool, regenerando o catalisador ${ }^{87}$ Para se ter uma noção da importância dos organoestânicos nesse processo, atribuindo-se 1 à velocidade relativa de reação na ausência de catalisador, esse parâmetro na presença de $\mathrm{Bu}_{2} \mathrm{SnCl}_{2}$ é 200, já na presença de óxidos ou alcóxidos organoestânicos, $\left[\left(\mathrm{Bu}_{2} \mathrm{SnO}\right)_{n}\right]$ e $\left[\mathrm{Bu}_{2} \mathrm{Sn}\left(\mathrm{OCOC}_{10} \mathrm{H}_{21}\right)_{2}\right]$ respectivamente, ocorre um aumento considerável na velocidade da reação para $40 \times 10^{3}$ e $56 \times 10^{3} .^{85}$ 


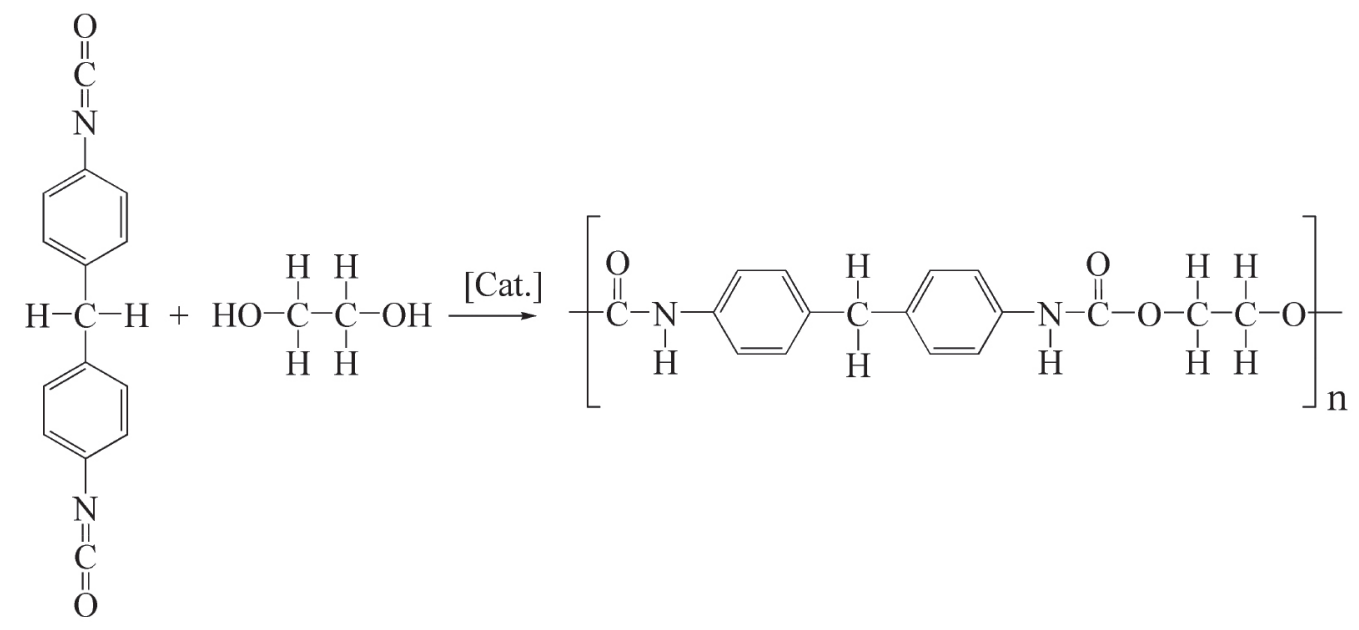

Figura 10. Reação padrão de obtenção de poliuretano

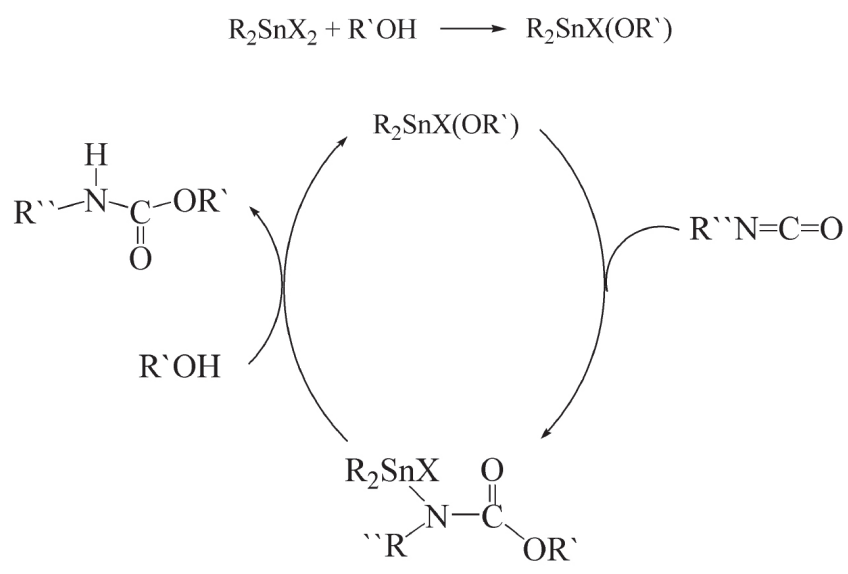

Figura 11. Mecanismo de ação de organoestânicos na obtenção de poliuretano

\section{Vulcanização de silicones}

Silicones são polímeros onde unidades de grupos siloxanos, -O-SiR $2-\mathrm{O}-$, se ligam formando polímeros multidimensionais, por exemplo o polidimetilsiloxano, Figura 12.<smiles>C[Si](C)(O)O[Si](C)(C)O[Si](C)(C)[Si](C)(C)O</smiles>

Figura 12. Estrutura do polidimetilsiloxano

Esses polímeros podem ser usados em diversas aplicações, como óleos, graxas, borrachas, resinas e selantes. Reações posteriores fazem com que os grupos $-\mathrm{OH}$ terminais formem ligações cruzadas convertendo óleos de silicone em elastômeros. Esse processo é chamado de vulcanização e pode ocorrer à temperatura ambiente através da reação entre um tipo de silicone e um trialquilsilano, catalisada por acetato ou dilaurato de dibutilestanho, Figura 13.

$\mathrm{O} \mathrm{Bu}_{2} \mathrm{Sn}(\mathrm{OAc}) \mathrm{OH}$ é produzido pela reação do diacetado de dibutilestanho com água. Na primeira etapa do mecanismo o material reage com $\mathrm{MeSi}(\mathrm{OMe})_{3}$, formando o intermediário $\mathrm{Bu}_{2} \mathrm{Sn}(\mathrm{OAc}) \mathrm{OSi}(\mathrm{OMe})_{2} \mathrm{Me}$. Na etapa final o grupo $-\mathrm{Si}(\mathrm{OMe})_{2} \mathrm{Me}$ é transferido para os grupos $-\mathrm{OH}$ do silicone, formando ligações do tipo -Si-O-Si-, e regenerando o catalisador. ${ }^{85}$

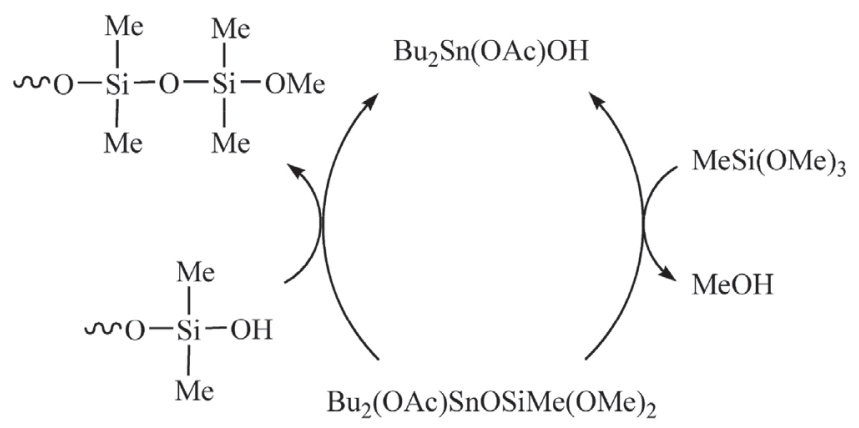

Figura 13. Mecanismo de ação do dilaurato de dibutilestanho na vulcanização do polidimetilsiloxano

\section{Organoestânicos aplicados em tintas anti-incrustantes}

A literatura científica mostra que o uso de tintas anti-incrustantes figura como uma antiga atividade humana ainda praticada nos dias de hoje, mas com graves impactos ambientais. A incrustação biológica é causada pelo acúmulo de algas, mexilhões e outros organismos nos cascos de embarcações trazendo sérios problemas, como a diminuição significativa da eficiência operacional, elevando os custos devido ao aumento do consumo de combustível. Produtos anti-incrustantes são empregados desde tempos remotos, quando eram utilizadas substâncias naturais como cera, piche e betume para revestir os cascos dos navios, que eram feitos de madeira ${ }^{88} \mathrm{Em}$ meados do século XIX surgiram às primeiras tintas anti-incrustantes tendo $0 \mathrm{Cu}_{2} \mathrm{O}$ o princípio ativo. No entanto, em pouco tempo essas tintas se tornaram ineficientes. Em 1961, foi desenvolvida a primeira tinta tendo um composto organoestânico como agente biocida, o óxido de tributilestanho, $\left(\mathrm{SnBu}_{3}\right)_{2} \mathrm{O} .{ }^{89} \mathrm{O}$ sucesso imediato fez aumentar drasticamente o uso de organoestânicos em novas formulações nas décadas seguintes. ${ }^{90}$ Desenvolveu-se também películas protetoras contendo um copolímero de acrilato e metacrilato de tributilestanho, que sofre hidrólise pela ação da água do mar, liberando lentamente a espécie tributilestanho (TBT), especialmente tóxica para animais marinhos.

A despeito dessa eficiência de compostos organoestânicos, estudos criteriosos divulgados na literatura começaram a mostrar os impactos ambientais e a toxicidade desses materiais para organismos não alvos. ${ }^{91}$ Observou-se que esses compostos afetam o desenvolvimento sexual de invertebrados, e como consequência impede seu ciclo reprodutivo. ${ }^{92}$ Destaca-se o desenvolvimento de caracteres sexuais masculinos em fêmeas destes animais ocasionado pela ruptura endócrina em gastrópodes ${ }^{93}$ Esse fenômeno, também conhecido como "imposex", é uma manifestação evidente de alterações endócrinas, 
que afetam hoje mais de 200 espécies em diferentes regiões do mundo..$^{94,95}$

Embora as tintas antiencrustantes tenham sido banidas na maioria dos países, é possível encontrá-las no comércio. O próprio cloreto de tributilestanho é facilmente obtido de empresas especializadas no fornecimento de reagentes químicos. Além disso, as principais fontes de contaminação são embarcações oriundas de lugares que não seguem a legislação internacional ou de países onde se pratica o uso clandestino desses produtos. A contaminação e acúmulo desses compostos na cadeia trófica pode trazer riscos reais aos seres humanos através da ingestão de alimentos contaminados, como peixes e frutos do mar.

\section{Outras aplicações do estanho}

Óxidos e sulfetos organoestânicos podem ser empregados na produção de $\mathrm{SnO}_{2}$ e $\mathrm{SnS}$ manométricos. ${ }^{96,97}$ Uma das importâncias do SnS é a possível substituição de calcogenetos de cádmio em tecnologias empregadas em células fotovoltaicas. Sulfetos de estanho, SnS e $\gamma-\mathrm{Sn}_{2} \mathrm{~S}_{3}$, são também produzidos através da decomposição térmica de ditiocarbamatos organoestânicos em condições controladas de temperatura e atmosfera. ${ }^{98}$

$\mathrm{O} \mathrm{SnO}_{2}$ dopado com $\mathrm{F}^{-}(3 \%)$ se transforma em um semicondutor do tipo n. Esse óxido pode também ser dopado com In(III), produzindo um semicondutor do tipo p, chamado ITO, bastante utilizado em dispositivos eletrônicos como diodos, transistores, células fotovoltaicas, janelas inteligentes e sensores, como um óxido condutor transparente, material condutor de eletricidade, porém transparente à radiação eletromagnética. Esse material pode ser preparado através da técnica chamada deposição de vapor químico (CVD em inglês) numa temperatura de $550^{\circ} \mathrm{C}$, empregando-se uma mistura de complexos de $\mathrm{In}(\mathrm{III})$ e de $\mathrm{Sn}(\mathrm{IV})$, como o $\mathrm{In}(\mathrm{dpm})_{3}$ e $\mathrm{SnBu}_{2}(\mathrm{OAc})_{2}$, Eq. $1 .{ }^{99}$

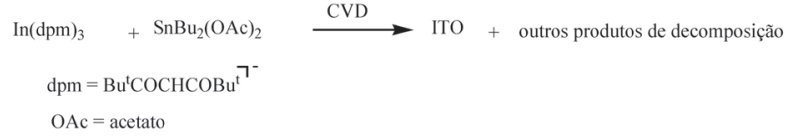

Dentre as interessantes aplicações do estanho destaca-se a fabricação da liga $\mathrm{Nb}_{3} \mathrm{Sn}$ que é um material cuja supercondutividade foi descoberta em 1954. Essa liga torna-se supercondutora abaixo de $18,3 \mathrm{~K}$, sua temperatura crítica, possibilitando sua aplicação como supermagnetos em aceleradores de partículas e em aparelhos de RMN, como os de 800 e $900 \mathrm{MHz} .{ }^{100}$

Uma das últimas descobertas em relação ao estanho foi a preparação, em 2016, de folhas de estanho com um átomo de espessura, cuja estrutura se assemelha à do grafeno. ${ }^{101} \mathrm{~A}$ existência desse material com características químicas similares ao do material de carbono havia sido predita através de cálculos teóricos em 2011. ${ }^{102}$ Essa descoberta poderá trazer consequências positivas, abrindo horizontes desconhecidos de pesquisa na área de novos materiais. ${ }^{103}$

\section{CONCLUSÃO}

A não ser que novas descobertas arqueológicas proporcionem uma mudança radical no entendimento da importância do estanho no mundo antigo, e de como o domínio da metalurgia contribuiu para o avanço da humanidade, pode-se concluir, tendo como base o conhecimento atual nesses tópicos, que esse metal teve um papel vital e estratégico nas conquistas humanas. A importância da Era do Bronze nesse contexto é inquestionável, possível, em virtude da existência desse metal. A partir do final da primeira metade do século XIX o estanho foi redescoberto graças ao desenvolvimento da química moderna, à consagração da revolução industrial e à dependência humana dos avanços tecnológicos. Não seria muito exagero concluir que os compostos de estanho, principalmente aqueles que são aplicados em reações catalíticas, fazem parte do grupo de substâncias mais importantes na atualidade, face ao emprego dos mesmos em processos industriais vitais. O Brasil se encontra inserido nesse processo, tendo em vista a sua participação no mercado mundial do estanho. Seria imprescindível que mais grupos brasileiros de pesquisa dedicassem esforços na descoberta de novos compostos, novos materiais e novos processos tecnológicos que agregassem valor ao mineral que extraímos de nosso subsolo. Afinal a história do Brasil, desde a colonização, nos mostra que matéria prima, manufatura e insumos básicos nunca trouxeram desenvolvimento e reais riquezas ao país. Ainda insistimos nesse modelo, nos esquecendo que tecnologia exige conhecimento e conhecimento gera tecnologia, riqueza e desenvolvimento social.

\section{REFERÊNCIAS E NOTAS}

1. Trigger, B. C.; A history of archaeological thought, $2^{\text {nd }}$ ed, Cambridge University Press: Cambridge, 1996.

2. Lilyquist, C.; Brill, R.H.; Studies in Ancient Glass, MMA: New York, 1993.

3. Gowland, W.; Journal of the Royal Anthropological Institute 1912, 42, 235.

4. Harrison, P. G.; Em Chemistry of Tin; $2^{\text {nd }}$ ed, Smith, P. J., ed, Springer Science Press: Glasgow, 1998, p1.

5. Barry, B. T. K.; Thwaites, C. J.; Tin and its Alloys and Compounds, Ellis Horwood: Chichester, 1983.

6. Frankland, E.; Liebigs Ann. Chem. 1849, 71, 171.

7. Frankland, E.; J. Chem. Soc. 1850, 2, 297.

8. https://www.dla.mil/HQ/Acquisition/StrategicMaterials.aspx, acessada em novembro 2019.

9. Ramos, C. R.; Novos Cadernos NAEA 2003, 6, 39.

10. http://www.anm.gov.br/dnpm/publicacoes/serie-estatisticas-e-economiamineral/sumario-mineral, acessada em novembro 2019.

11. Ingham, R.K.S.; Rosenberg, D.; Gilman. H.; Chem. Rev. 1960, 2, 459.

12. Neumann, P.; Chem. Rev. 1991, 91, 311.

13. Hitchcock, P.B.; Lappert, M.F.; Lawless, G.A.; Royo, B.; J. Chem. Soc., Chem. Commun. 1993, 554.

14. Davidson, P.J.; Harris, D.H.; Lappert, M. F.; J. Chem. Soc. Dalton Trans. 1976, 2268.

15. Jutzi P.; Dahlhaus J.; Coord. Chem. Rev. 1994, 137, 179.

16. Davidson, P. J.; Lappert, M. F.; J. Chem. Soc., Chem. Commun. 1973, 317.

17. Phillips, A. D.; Wright, R. J.; Olmstead, M. M.; Power, P. P.; J. Am. Chem. Soc. 2002, 124, 5930.

18. Roland, C. F.; Pu, L.; James, C. F.; Marcin, A. B.; Philip, P. P.; J. Am. Chem. Soc. 2006, 128, 11366.

19. Fässler, T. F.; Coord. Chem. Rev. 2001, 215, 347.

20. Hitchcock, P. B.; Lappert, M. F.; Pierssens, L. J.-M.; Protchenko, A.V.; Uiterweerd, P. G. H.; Dalton Trans. 2009, 4578.

21. Grignard, V.; C. R. Chim. 1900, 130, 1322.

22. Eisch, J.J.; Organometallics 2002, 21, 5439.

23. Tushar, M.; Baul, S.B.; Rivarola, E.; Hyperfine Interact. 2008, 185, 95.

24. de Lima, G. M.; Filgueiras C. A. L.; Quim. Nova 2010, 33, 2219.

25. de Lima, G. M.; Walton, R. I.; Clarkson, G. J.; Bitzer, R. S.; Ardisson, J. D.; Dalton Trans. 2018, 47, 8013.

26. de Lima, G. M.; Quim. Nova 2001, 24, 526.

27. Wilkinson, G.; Stone, F. G. A; Abel, E. W.; Comprehensive Organometallic Chemistry, $1^{\text {st }}$ ed, Pergamon Press: Oxford, 1982, Vol. 3,1043 .

28. Davidson, P. J.; Lappert, M. F.; J. Chem. Soc., Chem Commun. 1974, 895. 
29. Goldberg, D. E.; Hitchcock, P. B.; Lappert, M. F.; Thomas, K. M.; Thorne, A. J.; Fjeldberg, T.; Haaland, A.; Schilling, B. E. R.; J. Chem. Soc., Dalton Trans. 1986, 2387.

30. de Lima, G. M.; Duncalf, D. J.; Organometallics 1999, 18, 4884.

31. Janiak, C., Schumann, H., Hahn, E., Heeg, M., Kolax, J. C., Loebel, J., Rausch, M. D.; Zuckerman, J. J.; Chem. Ber. 1986, 119, 2656.

32. Burkey, D. J.; Hanusa, T. P., Organometallics 1995, 14, 11.

33. Constantine, S. P.; Hitchcock, P. B.; Lawless, G. A.; de Lima, G. M.; J. Chem. Soc., Chem. Commun. 1996, 1101.

34. Jutzi, P.; Kohl, F.; Hofmann, P.; Krüger, C.; Tsay, Y. -H.; Chem. Ber. 1980, 113, 757.

35. Wadepohl, H.; Pritzkow, H.; Siebert, W.; Organometallics 1983, 2, 1899.

36. Constantine, S. P.; de Lima, G. M.; Hitchcock, P. B.; Keates, J. M.; Lawless, G. A.; J. Chem. Soc., Chem. Commun. 1996, 2337.

37. de Lima, G. M.; Constantine, S. P.; Hitchcock, P. B.; Keates, J. M.; Lawless, G. A.; Marziano, I.; Organometallics 1997, 16, 793.

38. Reed, D.; Stalke, D.; Wright, D. S.; Angew. Chem., Int. Ed. Engl. 1991, 30, 1459.

39. Steiner, A.; Stalke, D.; J. Chem. Soc., Chem. Commun. 1993, 1702.

40. Reich, H. J.; Borst, J. P.; Dykstra, R. R.; Organometallics 1994, 13, 1.

41. Birchall, T.; Vetrone, J. A.; J. Chem. Soc., Chem. Commun. 1988, 877.

42. Arif, A. M.; Cowley, A. H.; Jones, R. A.; Power, J. M.; J. Chem. Soc., Chem. Commun. 1986, 1446.

43. Çetinkaya, B.; Gümrükçü, I.; Lappert, M. F.; Atwood, J. L.; Rogers, R. D.; Zaworotko, M. J.; J. Am. Chem. Soc. 1980, 102, 2088.

44. Arif, A. M.; Cowley, A. H.; Elkins, T. M.; J. Organomet. Chem. 1987, 325, C11.

45. Hitchcock, P. B.; Lappert, M. F.; Lawless, G. A.; Royo, B.; J. Chem. Soc., Chem. Commun. 1993, 554.

46. Paver, M. A.; Russel, C. A.; Stalke, D.; Wright, D. S.; Inorg. Chem. 1994, 33, 2370.

47. Westerhausen, M.; Angew. Chem., Int. Ed. Engl. 1994, 33, 1493.

48. Edwards, A. J.; Paver, M. A.; Raithby, P. R.; Russell, C. A.; Stalke, D.; Steiner, A.; Wright, D. S.; J. Chem. Soc., Dalton Trans. 1993, 1465.

49. de Lima, G. M.; Duncalf, D. J.; Main Group Met. Chem. 2000, 23, 395.

50. Davidson, M. G.; Stalke, D.; Wright, D. S.; Angew. Chem., Int. Ed. Engl. 1992, 31, 1226.

51. https://www.ccdc.cam.ac.uk/, acessada em novembro 2019.

52. Mitch, J.; Chem. Eng. News 2013, 91, 23.

53. Murray, L. J.; Dinca, M.; Long, J. R.; Chem. Soc. Rev. 2009, 38, 1294.

54. Ren, J. W.; Langmi, H. W.; North, B. C.; Mathe, M.; Int. J. Energy Res. 2015, 39, 607.

55. Cota I.; Martinez, F. F.; Coord. Chem. Rev. 2017, 351, 189.

56. Dong, Z.; Tan, R.; Cao, J.; Yang, Y.; Kong, C.; Du, J.; Zhu, S.; Zhang, Y.; Lu, J.; Huang B.; Liu, S.; Eur. J. Med. Chem. 2011, 46, 2477.

57. Bai, J. P.; Su, F.; Zhu, H. T.; Sun, H.; Zhang, L. C.; Liu, M. Y.; You, W. S.; Zhu, Z. M.; Dalton Trans. 2015, 44, 6423.

58. Day, R. O.; Chandrasekhar, V.; Swamy, K. C. K.; Holmes, J. M.; Burton, S. D.; Holmes, R. R.; Inorg. Chem. 1988, 27, 2887.

59. Holmes, R.; Acc. Chem. Res. 1989, 22, 190

60. Tiekink, E.R.T.; Trends 1994, 1, 71.

61. Chandrasekhar, V., Nagendran, S.; Baskar, V.; Coord. Chem. Rev. 2002, 235,1 .

62. Wardell, J. L.; Spencer, G. M. In Encyclopedia of Inorganic Chemistry; King, R. B., ed.; Wiley: Chichester, 2005, Vol. 9, 5590.

63. Davies, A. G. In Comprehensive Organometallic Chemistry III; Crabtree, R. H., Mingos, D. M., eds.; Elsevier: Oxford, 2007, Vol. 3, 809.

64. Tiekink, E. R. T.; Appl. Organomet. Chem. 2008, 22, 533.

65. https://www.bbc.com/news/magazine-21689069, acessada em novembro 2019.

66. Pode-se dizer que esta tenha sido uma das primeiras aplicações de folhas de Flandres.
67. http://www.oilcans.net/Research/American-Can-Company-1960.html, acessado em novembro 2019.

68. Chandler, B. V.; Clegg, K. M.; J. Sci. Food. Agric. 1970, 21, 315.

69. Tin Chemistry, Fundamentals, Frontiers and Applications; Davies, A. G., Gielen, M., Pannell, K. H., Tiekink, E. R. T., eds.; John Wiley and Sons Ltd: Chichester, 2008.

70. Dias, L. C.; Rubinger, M. M. M.; Baroli, J. P.; Ardisson, J. D.; Mendes, I. C.; de Lima, G. M.; Zambolim, L.; Oliveira, M. R. L.; Polyhedron, 2012, 47, 30.

71. Ferreira, I. P.; de Lima, G. M.; Paniago, E. B.; Rocha, W. R.; Takahashi, J. A.; Pinheiro, C. B.; Ardisson, J. D.; Eur. J. Med. Chem. 2012, 58, 493.

72. Rocha, C.S.; de Morais, B.P.; Rodrigues, B.L.; Donnici, C.L.; de Lima, G.M.; Ardisson, J.D.; Takahashi, J.A.; Bitzer, R.S.; Appl. Organomet. Chem. 2017, 31, e3645.

73. Vieira, F. T.; de Lima, G. M.; Maia, J. R. S.; Speziali, N. L.; Ardisson, J. D.; Rodrigues, L.; Junior, A. C.; Romero, O. B.; Eur. J. Med. Chem. 2010, 45,883 .

74. Vieira, F. T.; Menezes, D. C.; de Lima, G. M.; Wardell, J. L.; Cortés, M. E.; Silva, G. A. B.; Vilas Boas, A.; Maia, J. S.; Appl. Organomet. Chem. 2008, 22, 433 .

75. Menezes, D. C.; Vieira, F. T.; de Lima, G. M.; Wardell, J. L. Cortés, M. E.; Ferreira, M. P.; Soares, M. A.; Vilas Boas, A.; Appl. Organomet. Chem. 2008, 22, 221.

76. Menezes, D. C.; Vieira, F. T.; de Lima, G. M; Porto, A. O.; Cortés, M. E.; Ardisson, J. D.; Albrecht-Schmitt, T. E.; Eur. J. Med. Chem. 2005, 40,1277 .

77. Adeyemi, J. O.; Onwudiwe, D. C.; Molecules 2018, 23, 2571.

78. Perez-Rebolledo, A.; Ayala, J. D.; de Lima, G. M.; Marchini, N.; Bombieri, G.; Zani, C. L.; Souza-Fagundes, E. M.; Beraldo, H.; Eur. J. Med. Chem. 2005, 40, 467.

79. Florea, A. M.; Dopp, E.; Obe, G.; Rettenmeier, A. W.; Genotoxicity of organometallic species. Em Organic metal and metalloid species in the environment: analysis, distribution, processes and toxicological evaluation; Hirner, A.V., Emons, H. eds.; Springer-Verlag: Heidelberg, 2004, p. 205.

80. de Lima, G. M.; Vieira, F. T.; Maia, J. R. da S.; Speziali, N. L.; Ardisson, J. D.; Rodrigues, L.; Junior, A. C.; Romero, O. B.; Eur. J. Med. Chem. 2010, $45,883$.

81. Ahmad, A.; Khan, A.; Bharathi, N. P.; Hashmi, A. A.; Khan, L. A.; Manzoor, N.; Med. Chem. Res. 2011, 20, 1141.

82. Nath, M.; Vats, M.; Roy, P.; Eur. J. Med. Chem. 2013, 59, 310.

83. Ferreira, I. P.; de Lima, G. M.; Paniago, E. B.; Rocha, W. R.; Takahashi, J. A.; Pinheiro, C. B.; Ardisson, J. D.; Polyhedron 2014, 79, 161.

84. Yousif, E.; Journal of Taibah University for Science 2013, 7, 79.

85. https://www.statista.com/statistics/720341/global-polyurethane-marketsize-forecast/, acessada em novembro 2019.

86. https://flexivelpu.com.br/blog/o-mercado-brasileiro-do-poliuretano/, acessada em novembro 2019.

87. Davies, A. G.; J. Chem. Res. 2010, 4, 181.

88. Almeida, E.; Diamantino, T. C.; de Sousa, O.; Prog. Org. Coat. 2007, $59,2$.

89. Fent, K.; Toxicol. Lett. 2003, 353, 140

90. Martins, T. L.; Vargas, V. M. F.; Ecotoxicol. Environ. Contam. 2013, 8, 01.

91. Cristale, J.; Santos, D. M.; Sant'Anna, B. S.; Sandron, D. C.; Cardoso, S., Turrad, A.; Marchi, M. R. R.; J. Braz. Chem. Soc. 2012, 23, 39.

92. Ketata, I.; Denier, X.; Hamza-Chaffai, A.; Minier, C.; Comp. Biochem. Physiol. 2008, 147, 261.

93. Negri, A.; Marshall, P.; J. Environ. Manage. 2009, 90, S31.

94. Bigatti, G.; Primost, M. A.; Cledón, M.; Averbuj, A.; Theobald, N.; Gerwinski, W.; Mar. Pollut. Bull. 2009, 58, 695.

95. Dworkin, R. D.; Organotin PVC Estabilizers, PVC Primer, Society of Plastics Engineers, Bookfield: 1985. 
96. de Lima, G. M.; Sansiviero, M. T. C.; Lago, R. M.; Phys. Chem. Chem. Phys. 2000, 2, 5708.

97. de Lima, G. M.; Porto; A. O.; Siebald, H. G. L.; Silva, G. G.; Pereira, A. G.; Phys. Chem. Chem. Phys. 2002, 4, 4532.

98. de Lima, G. M.; Porto, A. O.; Ardisson, J. D.; Doriguetto, A. C.; Ellena, J.; Donnici, C. L.; Menezes, D. C.; Polyhedron 2004, 23, 2103.

99. Kane, J.; Schweizer, H. P.; Kern, W.; Thin solid Films 1975, 29, 155; Akinwunmi, O. O.; Eleruja, M. A.; Olowolafe, J. O.; Adegboyega G. A.; Ajayi, E. O. B. Opt. Mater. 1999, 13, 255.
100. Scanlan, R. M.; Malozemoff, A. P.; Larbalestier, D. C.; Proc. IEEE 1639, 92,2004

101. Deng, J.; Xia, B.; Ma, X.; Chen, H.; Shan, H.; Zhai, X.; Li, B.; Zhao, A.; Xu, Y.; Duan, W.; Zhang, S. C.; Wang, B.; Hou, J. G.; Nat. Mater. 2018, 17, 1081.

102. Garcia, J. C.; de Lima, D. B.; Assali, L. V. C.; Justo, J. F.; J. Phys. Chem. C 2011, 115, 13242.

103. Saxena, S.; Chaudhary, R. P.; Shukla, S.; Sci. Rep. 2016, 6, 31073. 